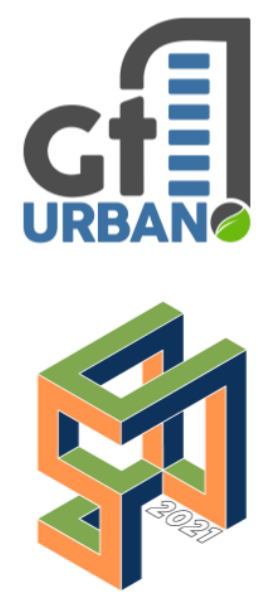

SINGEURB

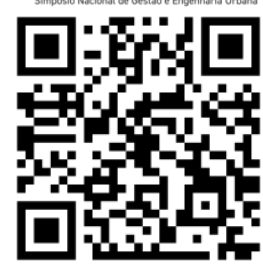

Como citar:

ARRUDA, Angela Maria; MASIERO,

Érico. Análise de índices de conforto térmico através dos softwares Rayman e ENVI-met em áreas industriais. In: III SIMPÓSIO NACIONAL DE GESTÃO E ENGENHARIA URBANA: SINGEURB, 2021, Maceió. Anais... Porto Alegre: ANTAC, 2021. p. 124137.

Disponível em: https://eventos.antac. org.br/index.php/sin geurb/issue/view/14

\title{
Análise de índices de conforto térmico através dos softwares Rayman e ENVI-met em áreas industriais
}

\author{
Analysis of thermal comfort indices through \\ Rayman and ENVI-met software in industrial
}

\section{areas}

Angela Maria Arruda, Universidade Federal de São Carlos, angelaarruda@estudante.ufscar.br Érico Masiero, Universidade Federal de São Carlos, erico@ufscar.br

\section{RESUMO}

A radiação solar é um dos parâmetros que influenciam no conforto térmico humano. A temperatura média radiante (Tmrt) é um dos quatro parâmetros ambientais, assim como temperatura do ar, a umidade relativa e a velocidade do vento, que interferem no equilíbrio energético humano. $O$ fator de visão do céu (FVC) relaciona-se com a radiação direta e difusa, visto que representa o quanto de obstáculos estão presentes na geometria urbana e que podem interferir no ganho ou perda de calor. O índice de temperatura equivalente fisiológica (PET) e o índice climático térmico universal (UTCI) são índices de conforto térmico indicados para o estudo de espaços abertos. A medição in loco de tais índices envolvem equipamentos caros e um processo trabalhoso. Como alternativa tem-se as simulações computacionais através de softwares bioclimáticos como ENVI-met e Rayman. Sob essa ótica, esse trabalho estimou os índices PET e UTCI em uma área industrial, através desses softwares, bem como variáveis pertinentes ao estudo para comparação os resultados obtidos. Seguindo a literatura, os resultados obtidos através do software Rayman foram inferiores àqueles fornecidos pelo ENVI-met, principalmente em períodos de incidência solar.

Palavras-chave: Índices de conforto térmico, ENVI-met, Rayman.

\section{ABSTRACT}

Solar radiation is one of the parameters that influence human thermal comfort. The average radiant temperature (Tmrt) is one of the four environmental parameters, as well as air temperature, relative humidity and wind speed, which interfere with human energy balance. The sky view factor (FVC) is related to direct and diffuse radiation, as it represents how many obstacles are present in the urban geometry and that can interfere with heat gain or loss. The physiological equivalent temperature index (PET) and the universal thermal climate index (UTCI) are thermal comfort indices indicated for the study of open spaces. On-site measurement of such indices involves expensive equipment and a labor-intensive process. As an alternative, there are computer simulations using bioclimatic software such as ENVI-met and Rayman. From this perspective, this work estimated the PET and UTCI indices in an industrial area, through these software, as well as variables relevant to the study to compare the results obtained. Following the literature, the results obtained through the Rayman 
software were inferior to those provided by the ENVI-met, mainly in periods of solar incidence.

Keywords: Thermal comfort indices; ENVI-met; Rayman.

\section{INTRODUÇÃO}

A radiação é o parâmetro que governa o conforto térmico humano em dias de céu claro. A temperatura média radiante (Tmrt) é um dos quatro parâmetros ambientais, assim como temperatura do ar, a umidade relativa e a velocidade do vento, que interferem no equilíbrio energético humano (GÁL, KANTOR, 2020). Além da temperatura superficial e a incidência de radiação solar, o fator de visão do céu - FVC -, parâmetro adimensional representativo da relação geométrica entre e Terra e o céu estipulando o trecho visível de céu (SOUZA et al., 2010), pode também influenciar o fluxo de ondas curtas e longas sobre as superfícies urbanas.

O efeito da radiação no conforto térmico é mensurado pela temperatura média radiante (Tmrt) que expressa troca de radiação de onda curta e longa de um corpo humano padrão em graus Celsius e pode ser medida por diferentes métodos. Gál e Kántor (2020) verificaram a performance de três modelos de microclimas e sua habilidade de estimar valores de (Tmrt) em ambientes urbanos complexos, neste caso, uma praça central de uma cidade de porte médio da Hungria. Resultados mostraram que os modelos sistematicamente subestimam (Tmrt) no período noturno. Os modelos SOLWEIG e ENVI-MET tendem a superestimar os resultados durante período prolongados de sombra e subestimar quando há luz solar.

Nince et al. (2013) estudaram a aplicabilidade dos índices de temperatura equivalente fisiológica (PET), definido como balanço térmico do corpo humano mantido com as temperaturas centrais e as da pele iguais para aquelas condições avaliadas, e índice climático térmico universal (UTCI), temperatura do ar ambiente de referência que gera o mesmo valor de estresse térmico do ambiente real, na avaliação do conforto térmico em Cuiabá/MT.

Foram distribuídas unidades de medição em quatro pontos do campus da UFMT em períodos de climas contrastantes: quente e úmido e quente e seco. Comprovou-se a importância de proporcionar sombreamento em espaços abertos em climas tropicais. O PET ultrapassou $50{ }^{\circ} \mathrm{C}$, nos dois períodos, em horas críticas. A grama, o concreto e o asfalto apresentam índices de até $43{ }^{\circ} \mathrm{C}$, classificando como estresse de calor extremo.

Já Kruger et al. (2018) afirmam que as condições climáticas associadas à análise da relação do conforto térmico, em especial de índices de conforto como PET, constituem ferramentas fundamentais para o planejamento urbano. O estudo definiu faixas de conforto térmico para espaços externos em Curitiba/PR no intervalo de $16,2{ }^{\circ} \mathrm{C}$ a $22,9{ }^{\circ} \mathrm{C}$.

Szucs et al. (2015) explicam que a determinação dos dados a partir de medições com termômetro-globo, piranômetro e pirgeômetro para quantificar os fluxos de radiação nas seis direções geram dados precisos porém custosos.

Sendo assim as simulações numéricas computacionais de climatologia urbana são uma opção para o estudo dos índices de conforto térmico em áreas urbanas. 
O tema proposto para este trabalho surge da necessidade de obter informações sobre os principais índices térmicos PET e UTCI de acordo com simulações computacionais através dos softwares Rayman e ENVImet para uma região industrial da cidade de São Carlos/SP, tendo em vista que tais regiões podem impactar significativamente no equilíbrio climático devido ao uso excessivo de coberturas metálicas e materiais altamente impermeáveis com elevada condutividade térmica das construções.

\section{MÉTODOS}

O desenvolvimento do método desta pesquisa foi divido nas seguintes etapas:

- Caracterização física de um recorte de uma área urbana selecionada no tamanho de $400 \mathrm{~m}$ x $400 \mathrm{~m}$ com uso predominantemente industrial;

- Caracterização da geometria urbana dos recortes estudados a partir do sistema de classificação de Zonas Climáticas Locais - ZCLs de Stewart e Oke (2012) e dos materiais utilizados nas construções;

-Desenvolvimento de modelagem e simulações computacionais do recorte urbano industrial através dos softwares ENVI-met e Rayman (Versão XX) para determinação dos índices conforto térmico PET e UTCI em dois pontos distintos.

\subsection{Caracterização da área de estudo selecionada}

A cidade de São Carlos/SP está localizada no interior do estado de São Paulo, 22 $01^{\prime} 02^{\prime \prime}$ S e 4753'26" O, na região centro-oeste com população estimada de 254.484 habitantes (IBGE, 2020) e área total de 1.136.907 $\mathrm{km}^{2}$. É um importante centro regional industrial e sua economia baseada em atividades industriais e agropecuárias. O clima é subtropical úmido na classificação de Köppen-Geiger, altitude de 856 m, IDH de 0,805 segundo (IBGE 2019).

Para o estudo, foi selecionado um recorte localizado no distrito industrial da cidade de São Carlos/ SP apresentado na Figura 1.

Figura 1 - Localização do recorte estudado

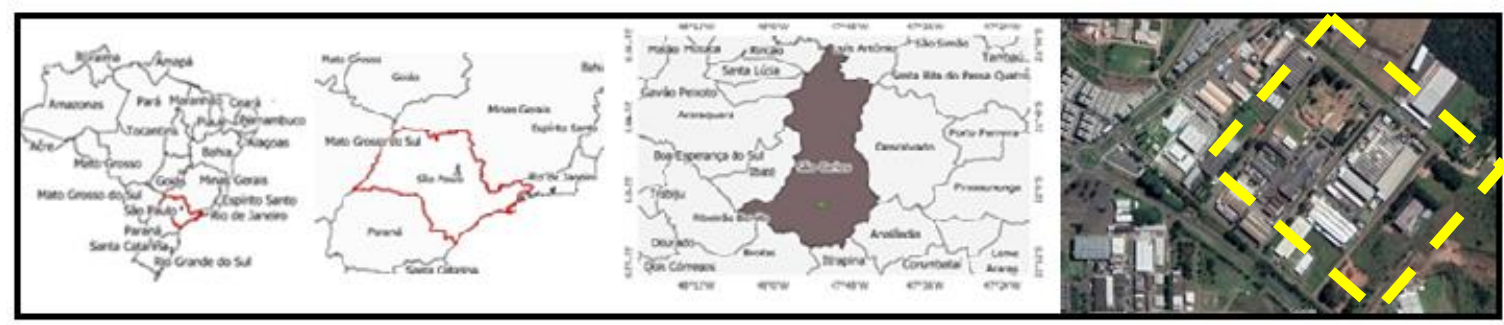

Fonte: Adaptado de Google Maps (2021)

A estação meteorológica do INMET (INMET, 2021), utilizada como referência e dados meteorológicos, fica localizada no campus da UFSCar, a aproximadamente $7 \mathrm{~km}$ ao norte receptores área de estudo.

O distrito industrial está localizado na zona climática local (ZCL) 8, composta por galpões baixos de grande porte, de 1 a 3 andares, poucas ou nenhuma árvore, cobertura do solo pavimentado com material impermeável. Os materiais amplamente utilizados nas superfícies são aço, concreto, metal, pedra e asfalto 
(OKE, 2012). No recorte estudado, 52\% da área é composta por asfalto, seguida por $25 \%$ de vegetação e $19 \%$ de telhado.

\subsection{Simulação dos recortes utilizando software ENVI-met e Rayman}

O modelo do ENVI-met foi definido com $400 \mathrm{~m}$ x $400 \mathrm{~m}$, grid de $4 \mathrm{~m} \times 4 \mathrm{~m}$ e rotacionado $38^{\circ}$ sentido antihorário para facilitar a modelagem e simulação (Figura 2). Após a caracterização física dos elementos que compõem a área, foram posicionados dois receptores para registrar dados ao longo das $24 \mathrm{~h}$ de simulação.

Figura 2- (a) Imagem do recorte estudado; (b) Modelagem no ENVI-met
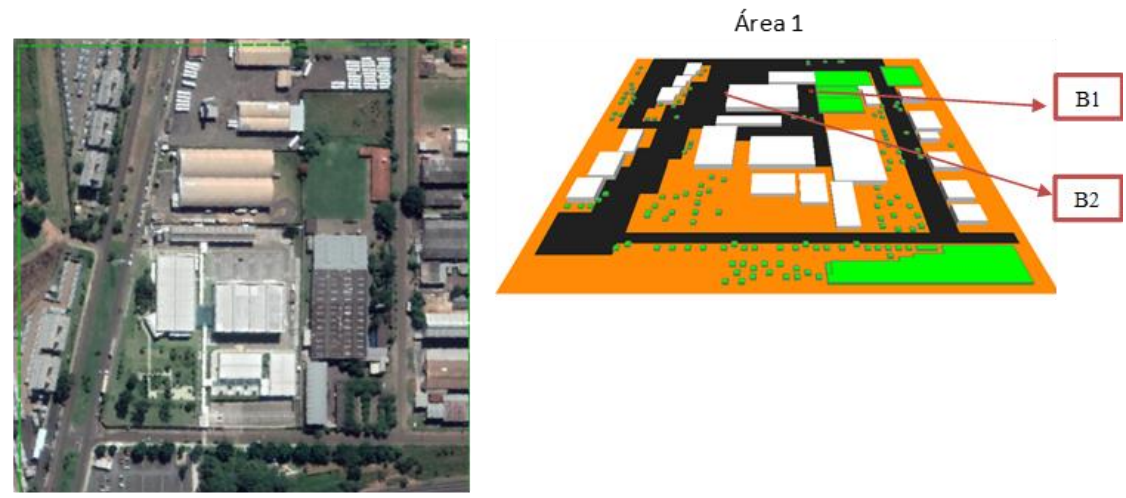

(a)

(b)

Fonte: Os autores (2021)

Os dados introduzidos no ENVImet para a realização da simulação, na ferramenta ConfigWizard são apresentados na Tabela 1:

Tabela 1: Dados de entrada para simulação ENVI-met

\begin{tabular}{|c|c|}
\hline Dados & Valores \\
\hline $\begin{array}{c}\text { Localidade / Coordenadas } \\
\text { Geográficas }\end{array}$ & São Carlos/SP $22^{\circ} 01^{\prime} 02^{\prime \prime} \mathrm{S}, 4^{\circ} 53^{\prime} 26^{\prime \prime} \mathrm{O}$ \\
\hline Data (início da simulação) & $04 / 04 / 2021$ \\
\hline Duração da simulação & $24 \mathrm{~h}$ \\
\hline $\begin{array}{l}\text { Vel. Vento a } 10 \mathrm{~m} \text { da superfície } \\
\qquad(\mathrm{m} / \mathrm{s})\end{array}$ & 1,74 \\
\hline Direção do vento & SO \\
\hline Comprimento de rugosidade & 0,01 \\
\hline
\end{tabular}

Fonte: Os autores

Os valores de variação de temperatura do ar e umidade relativa foram obtidos no site do INMET (2021), na estação meteorológica de São Carlos- A701, dia 04/04/2021 o qual é caracterizado com céu claro, sem precipitações, vento fraco e altas temperaturas.

A simulação realizada no software Rayman foi realizada no mesmo dia para um indivíduo de 1,75 m, 75 $\mathrm{kg}$, sexo masculino, atividade de $80 \mathrm{~W}$ e 0,9 clô. 
Na Figura é mostrado o posicionamento dos receptores B1 e B2, respectivamente. O diagrama polar demonstrando a posição do sol em diferentes horários do dia, bem como a obstrução do céu expressada em termos do fator de visão do céu (FVC) é mostrado nas Figuras 3 e 4.

Figura 3: Posicionamento dos receptores no programa Rayman

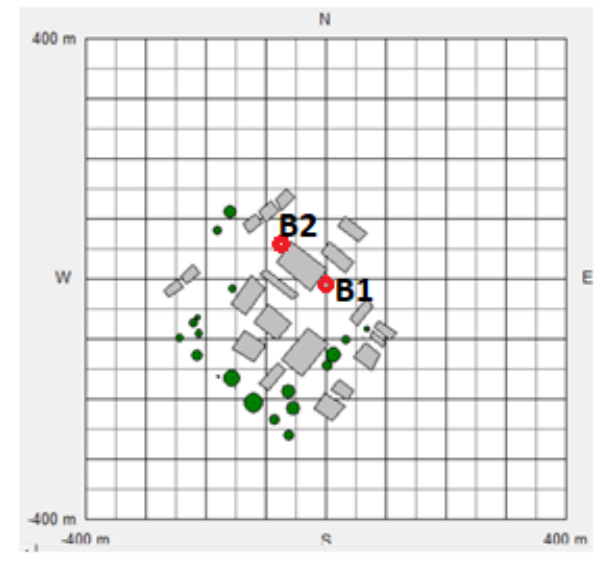

Fonte: Os autores (2021)

\section{RESULTADOS}

Nessa seção são apresentados os resultados encontrados para os parâmetros e índices climáticos do recorte simulado através do ENVI-met e Rayman.

3.1 Fator de visão do céu (FVC) e temperatura de superfície (Ts)

Na Figura 4 são mostrados os FVCs simulados pelo Rayman e ENVI-met. Nos dois pontos estudados os FVC variaram de 0,88 para B2 e 0,91para B1, sendo os resultados obtidos pelos softwares similares entre si. 
Figura 4: FVCs dos pontos B2 e B1 Rayman e ENVI-met

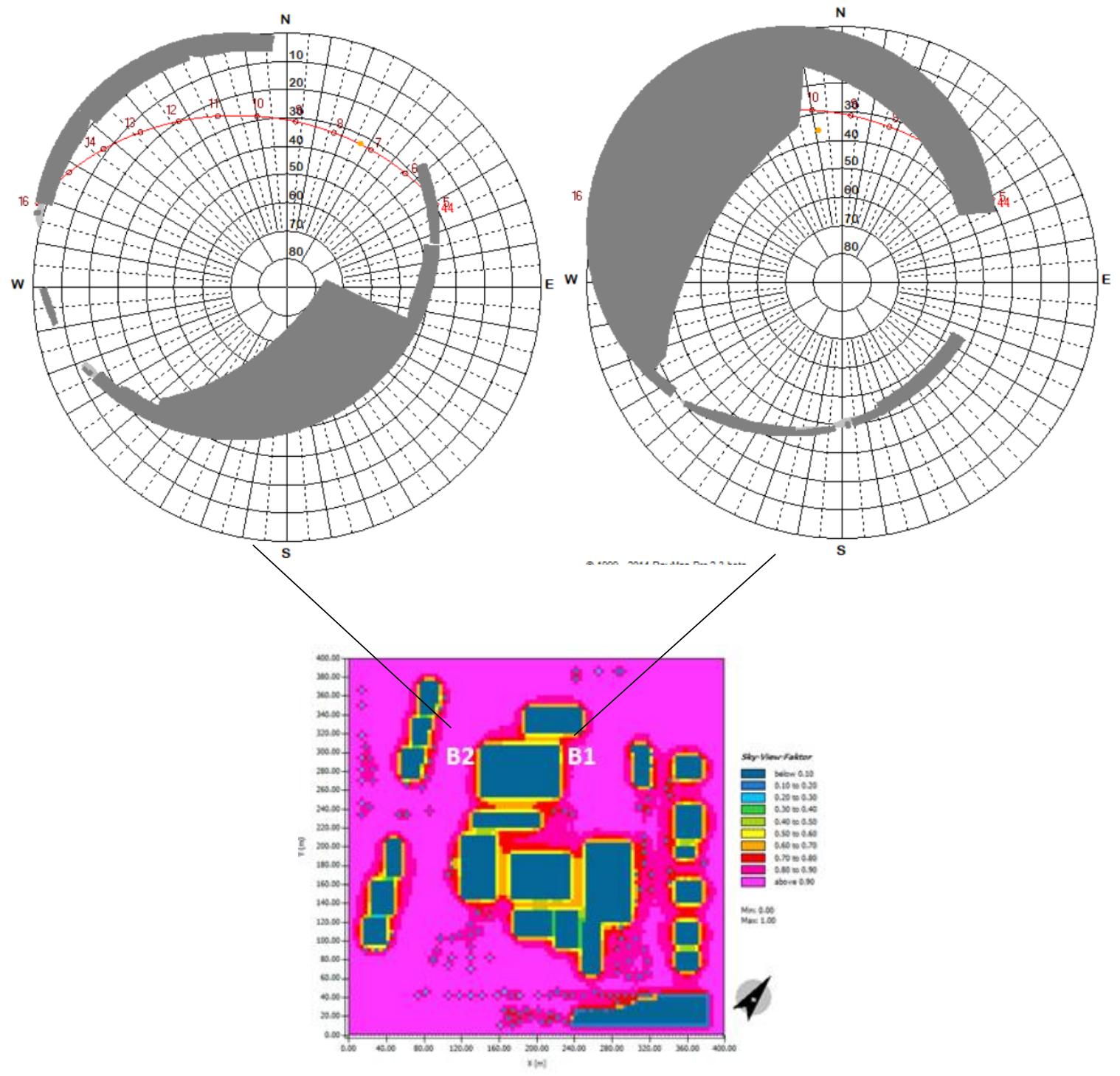

Fonte: Os autores (2021)

Percebe-se através da localização de B1 que tal ponto recebe radiação solar num período mais curto (somente algumas horas da manhã). Já o ponto B2 recebe radiação solar o dia todo. Todavia, a incidência de radiação solar direta aparentemente não influencia na temperatura da superfície dos pontos estudados no horário de maior temperatura $(15 \mathrm{~h})$. Tal constatação fundamenta-se na influência de vários parâmetros que contribuem para o aumento da temperatura do ar, entre eles as propriedades radiantes dos materiais construtivos, tais como a emissividade e o albedo, a velocidade do vento, a umidade relativa do ar e a presença de vegetação.

Quanto mais claras as cores, melhores são essas propriedades radiantes e esses materiais são denominados frios (emissividade de 92\% e refletância de 75\%). Já materiais escuros, ou corpos negros, apresentam emissividade de $92 \%$ e refletância de apenas $5 \%$. Os telhados metálicos presentes nesse estudo são capazes de refletir $60 \%$ da radiação solar que recebem e emitir para o entorno $25 \%$ da radiação (GARTLAND, 2010). 
Vale ressaltar, que no recorte estudado $52 \%$ da área é composta por asfalto, seguida por $25 \%$ de vegetação e 19\% de telhado. O albedo da ZCL 8 varia de 0,15 a 0,25, que se justifica pela presença de materiais com baixo albedo, segundo o sistema de classificação elaborado por STEWART e OKE, 2012.

Figura 5: Temperatura de superfície

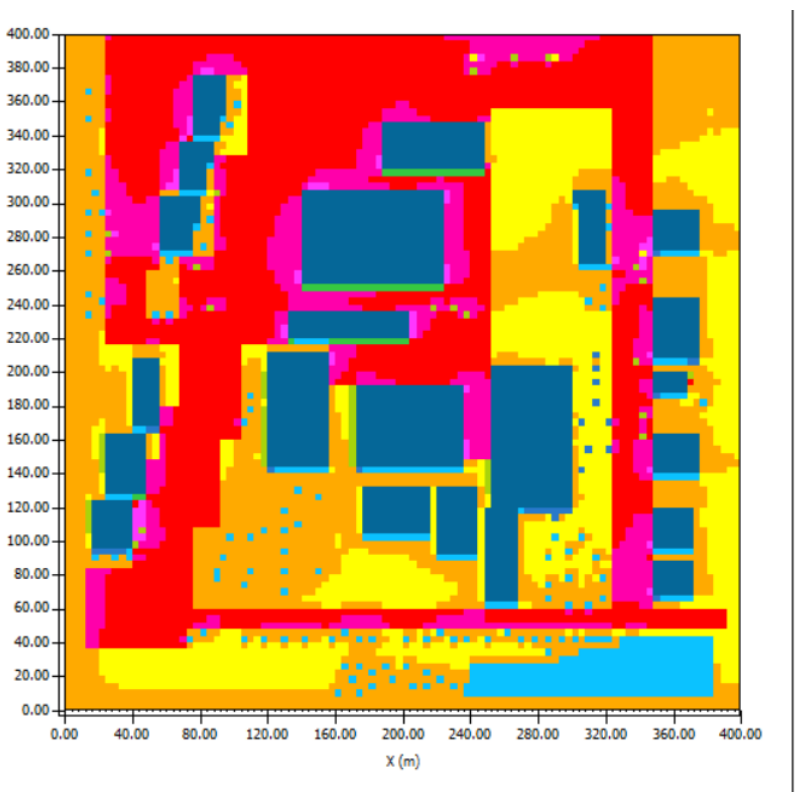

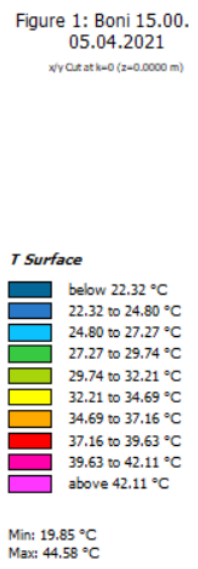

Min: $19.85^{\circ} \mathrm{C}$

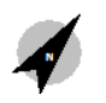

Fonte: Os autores (2021)

\subsection{Temperatura média radiante ( $\mathrm{Tmrt}$ )}

Para os dados simulados neste trabalho e mostrados na Figura 6, a diferença média entre os modelos ENVImet e Rayman para o período com incidência solar atinge aproximadamente $48 \%$.

Szucs et al. (2015) simularam e mediram a Tmrt em um bairro de Lisboa através dos softwares Rayman, ENVI-met e SOLVEIG. O cálculo da Tmrt pelos métodos numéricos conduziram a resultados diferentes se comparados aos medidos: nos locais ao sol, os valores obtidos por RayMan e SOLWEIG são os que mais se aproximam dos valores medidos (diferenças médias de $6 \%$ e $9 \%$, respectivamente), ao passo que ENVImet os superestima em 20\%; nos locais à sombra, ENVi-met fornece o melhor resultado, ao passo que RayMan e SOLWEIG superestimam os valores em $15 \%$. 
Figura 6: Variação Média da Tmrt no ENVI-met e no Rayman

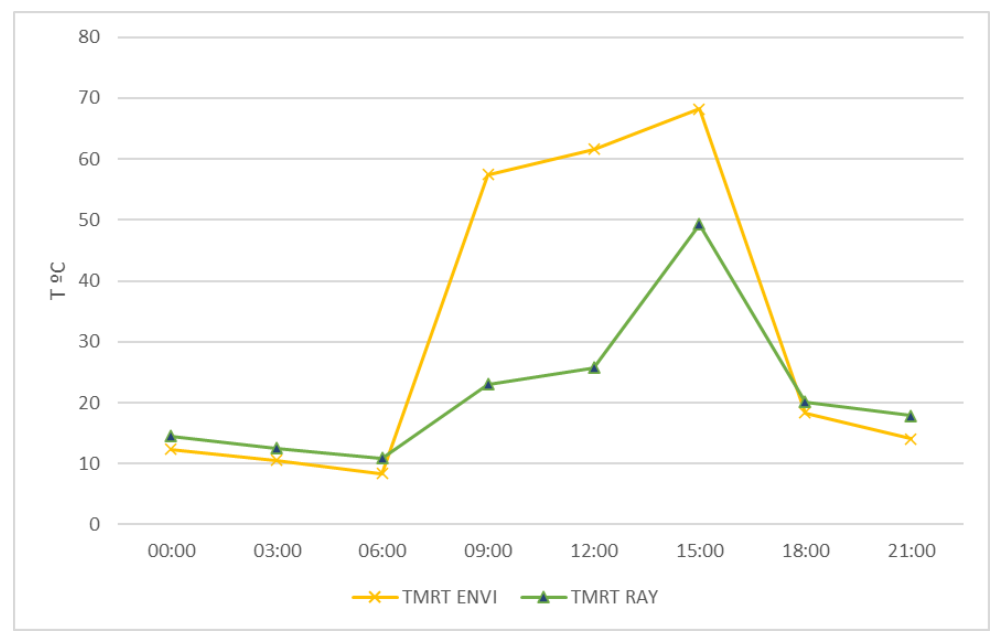

Fonte: Os autores (2021)

Os resultados para as posições B1 e B2 são mostrados na Figura 7, onde T é a temperatura do ar segundo INMET:

Figura 7: Variação da Tmrt entre os receptores B1 (Tmrt 1) e B2 (Tmrt 2) (a) ENVI-met e (b) Rayman

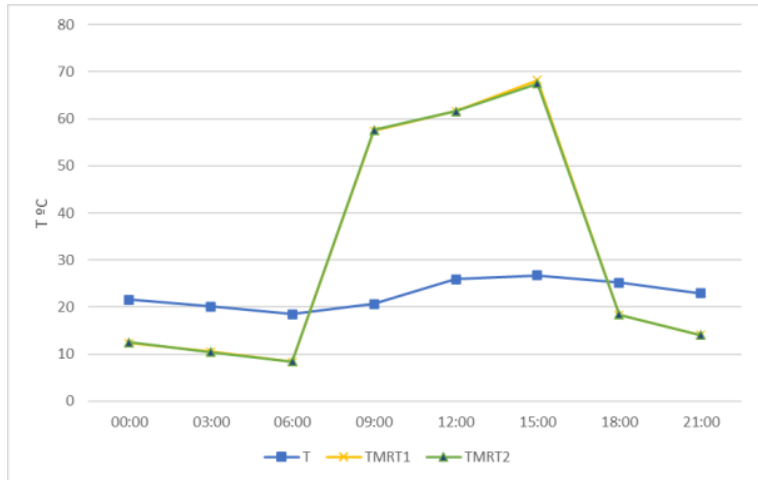

(a)

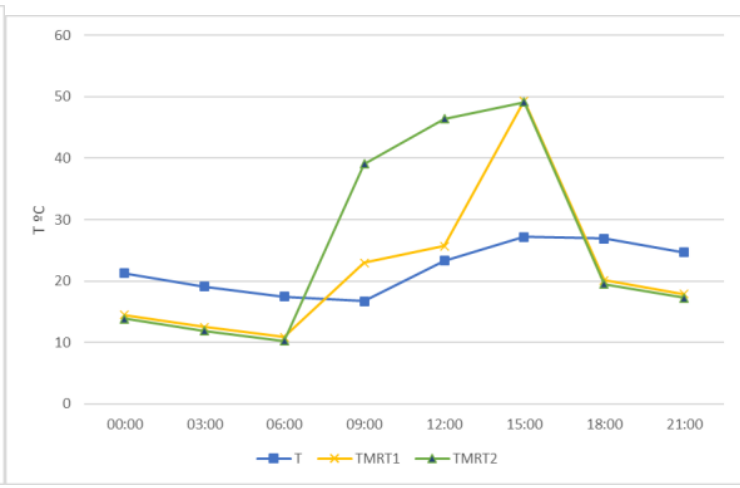

(b)

Fonte: Os autores (2021)

Para a simulação no ENVI-met a Tmrt apresentou valores próximos, já o software Rayman apresentou valores distintos para os pontos estudados. Talvez este segundo seja mais sensível ao FVC e à taxa de horizonte obstruído, visto que a insolação nos pontos é distinta. A uniformidade dos valores para Tmrt simulados pelo ENVI-met no período das $12 \mathrm{~h}$ às $15 \mathrm{~h}$ é apresentada na Figura 8 . Percebe-se que a partir das $18 \mathrm{~h}$ ocorre uma mudança no padrão da Tmrt. 
Figura 8: $\mathrm{T}_{\mathrm{mrt}}$ às $12 \mathrm{~h}, 15 \mathrm{~h}$ e $18 \mathrm{~h}$ pelo ENVIMET
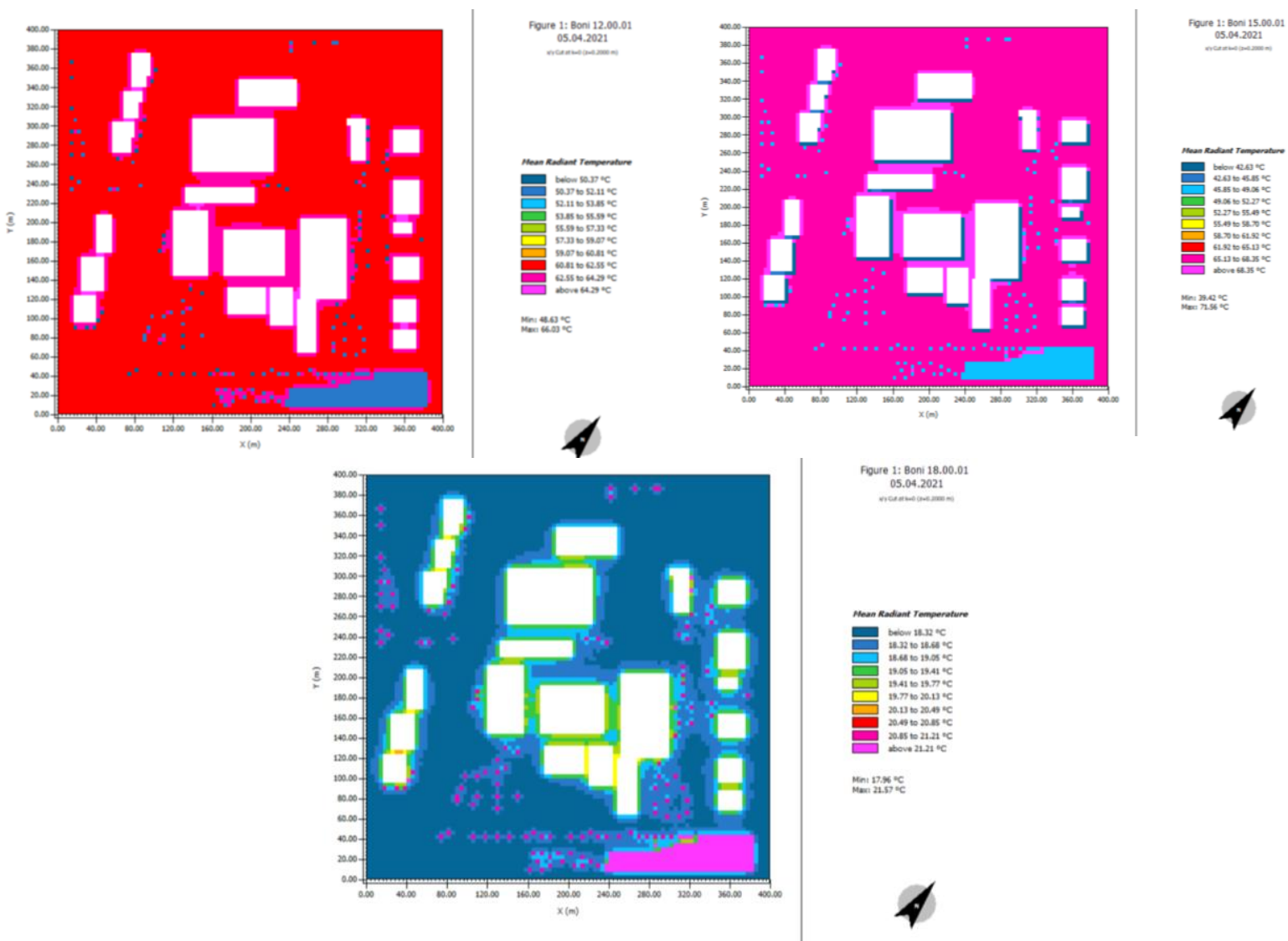

$\ln x=\pi$

Fonte: Os autores (2021)

Andrade e Romero (2018) identificaram a influência da radiação solar direta sobre Tmrt, áreas com maior vegetação apresentaram menor temperatura nas áreas sombreadas entre $12 \mathrm{~h}$ e $15 \mathrm{~h}$, sendo que a situação se inverte a partir das $18 \mathrm{~h}$, pois o calor acumulado durante o dia passa a ser liberado para o ambiente, corroborando o estudo aqui apresentado.

Figura 9: (a) Velocidade do vento, (b) temperatura do ar e (c) fluxo de calor do solo

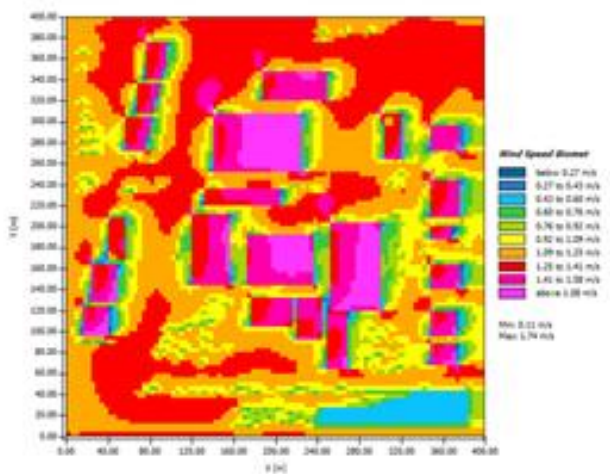

(a)

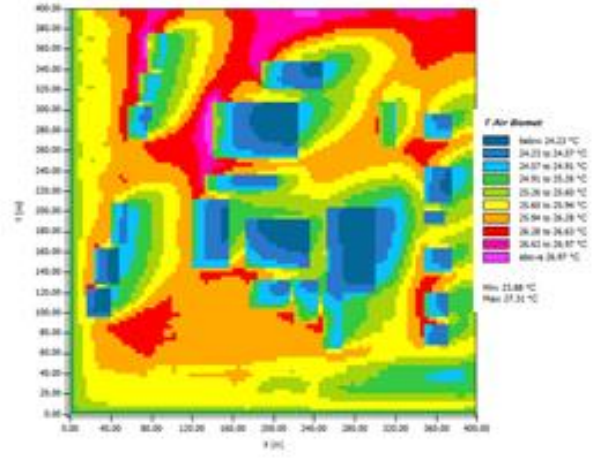

(b) 


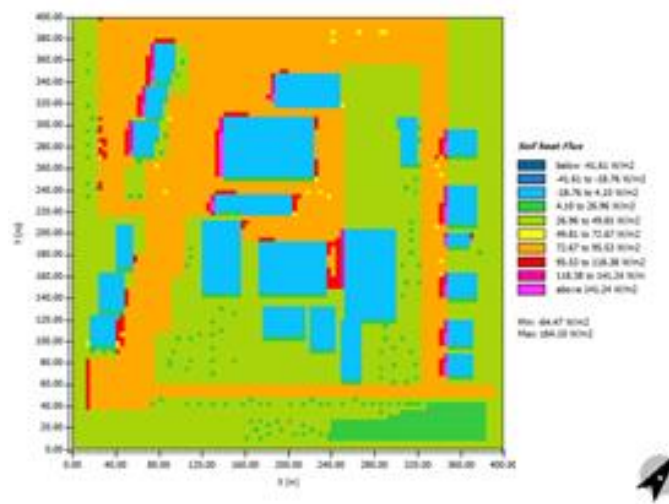

(c)

Fonte: Os autores (2021)

3.3 Índice de temperatura equivalente fisiológica (PET)

Em relação ao PET os valores simulados pelo ENVI-met se mantiveram próximos independente do período estudado; já os dados obtidos pelo Rayman apresentam diferenças da ordem de $25 \%$ em média para o período das 6 às $15 \mathrm{~h}$ (Figura 10).

Figura 10: PET dos receptores estudados B1 (PET1) e B2 (PET2) para (a) ENVI-met e (b) Rayman

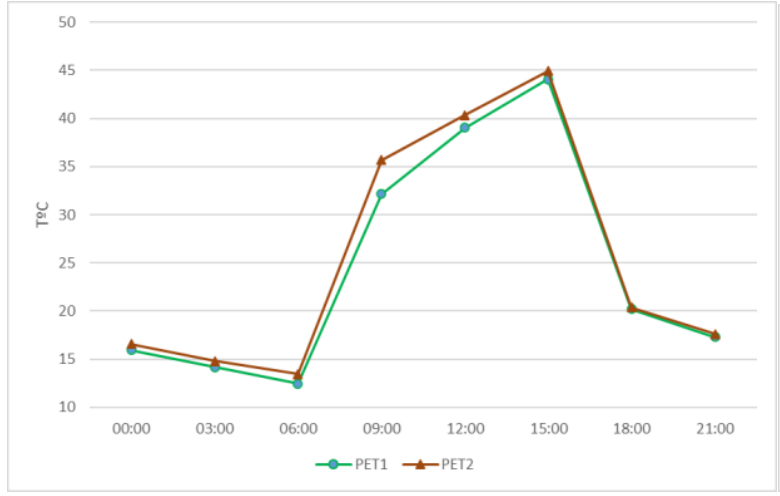

(a)



(b)

Fonte: Os autores (2021)

Ao comparar os resultados dos softwares os resultados fornecidos pelo ENVI-met mantiveram a tendência de serem maiores no período de incidência solar. 
Figura 11: Valores de PET estimados pelo ENVI-met e Rayman

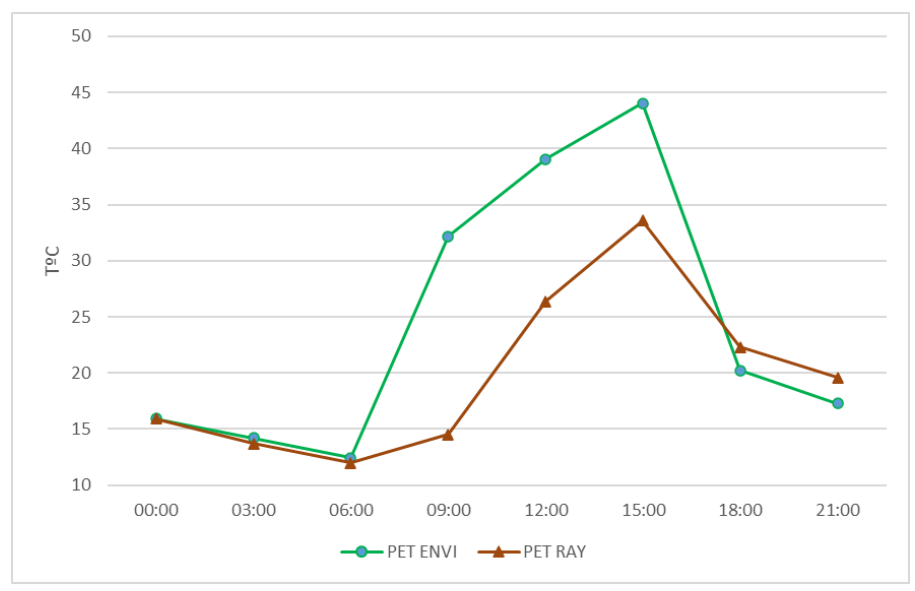

Fonte: Os autores (2021)

O índice térmico PET segundo a simulação pelo Rayman variou de $11,9^{\circ} \mathrm{C}$ a $33,4^{\circ} \mathrm{C}$, ou seja, de ligeiramente frio a calor moderado. Já para o ENVI-met os resultados variaram de ligeiramente frio a forte estresse de calor de acordo com classificação de Matzarakis e Mayer (1996).

Para melhorar os índices de conforto pode-se adotar diferentes abordagens: Shinzato e Duarte (2018) constataram que uma redução de $0,7^{\circ} \mathrm{C}$ na temperatura do ar somada à diferença de $15^{\circ} \mathrm{C}$ na Tmrt pode reduzir em até $7^{\circ} \mathrm{C}$ a PET percebida pelo usuário, mesmo havendo redução de $34 \%$ na velocidade do vento.

\section{4 Índice climático térmico universal (UTCI)}

Os valores apresentados pelo ENVI-met para o UTCI variaram de $15,55^{\circ} \mathrm{C}$ a $36,53^{\circ} \mathrm{C}$ e pelo Rayman de $13,6^{\circ} \mathrm{C}$ a $31,7^{\circ} \mathrm{C}$ classificados entre nenhum estresse a estresse de calor forte. Na figura apresenta-se os dois pontos simulados: no ENVI-met não ocorrem diferenças significativas já para o Rayman as diferenças ocorrem das $6 \mathrm{~h}$ às $15 \mathrm{~h}$.

Figura 12: UTCI dos receptores estudados para ENVI-met e Rayman

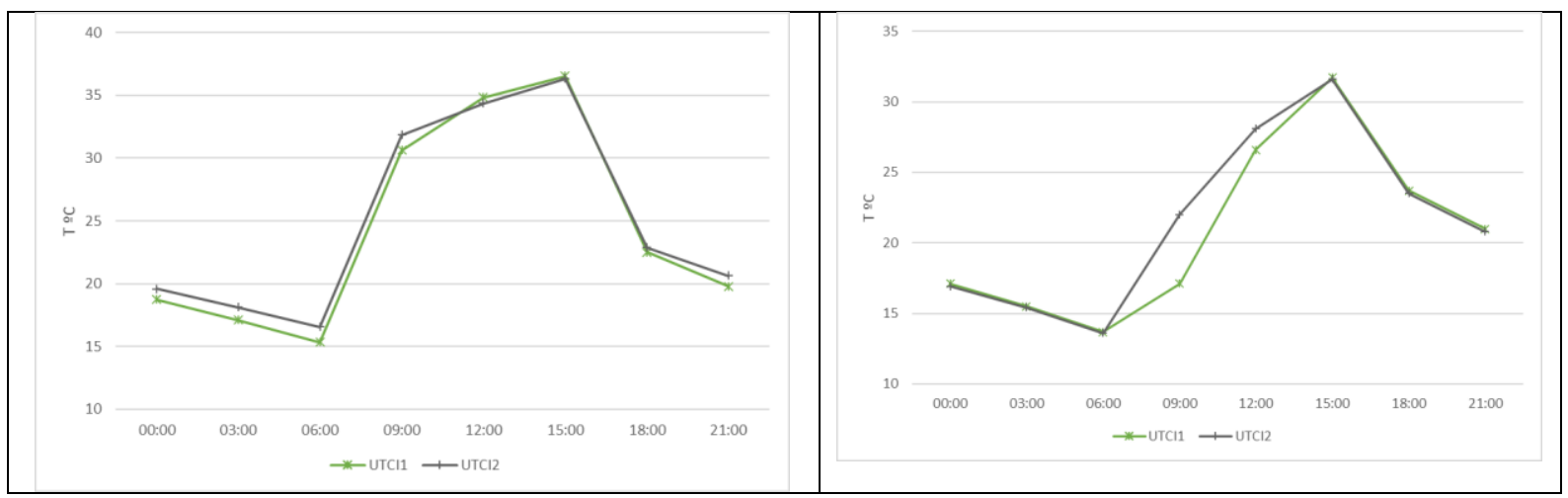

Fonte: Os autores (2021)

Seguindo as tendências das variáveis medidas anteriormente, os valores encontrados pelo Rayman foram inferiores se comparados aos valores previstos pelo ENVI-met. 
Figura 13: Valores estimados pelo ENVI-met e Rayman

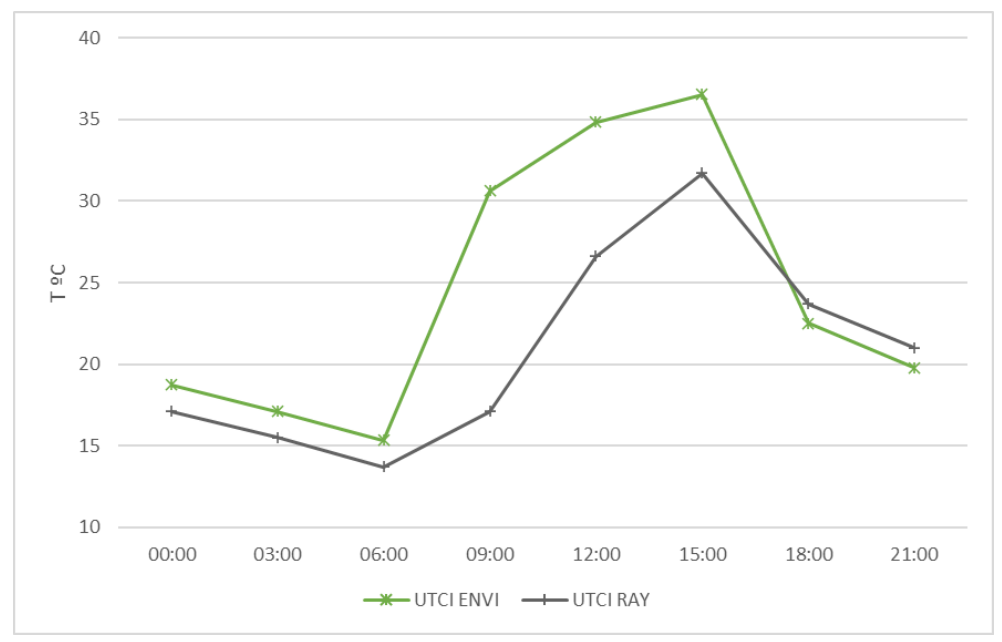

Fonte: Os autores (2021)

Ribeiro et al. (2021) utilizaram o Rayman e questionários para o inferir os valores de UTCI em Cuiabá/MT e concluíram que a menor variação de temperatura do ar e UTCI foram observadas no cenário arborizado, sendo que este último índice variou de 32,0 a $37,5^{\circ} \mathrm{C}$ (período quente-úmido) e de 22,6 a $31,8^{\circ} \mathrm{C}$ quenteseco.

Neste trabalho a área coberta por vegetação no horário de pico ( $15 \mathrm{~h})$ o UTCI variou de $33^{\circ} \mathrm{C}$ a $33,95^{\circ} \mathrm{C}$ seguindo a tendência do estudo de Ribeiro (2021).

Figura 14: UTCI das diferentes áreas

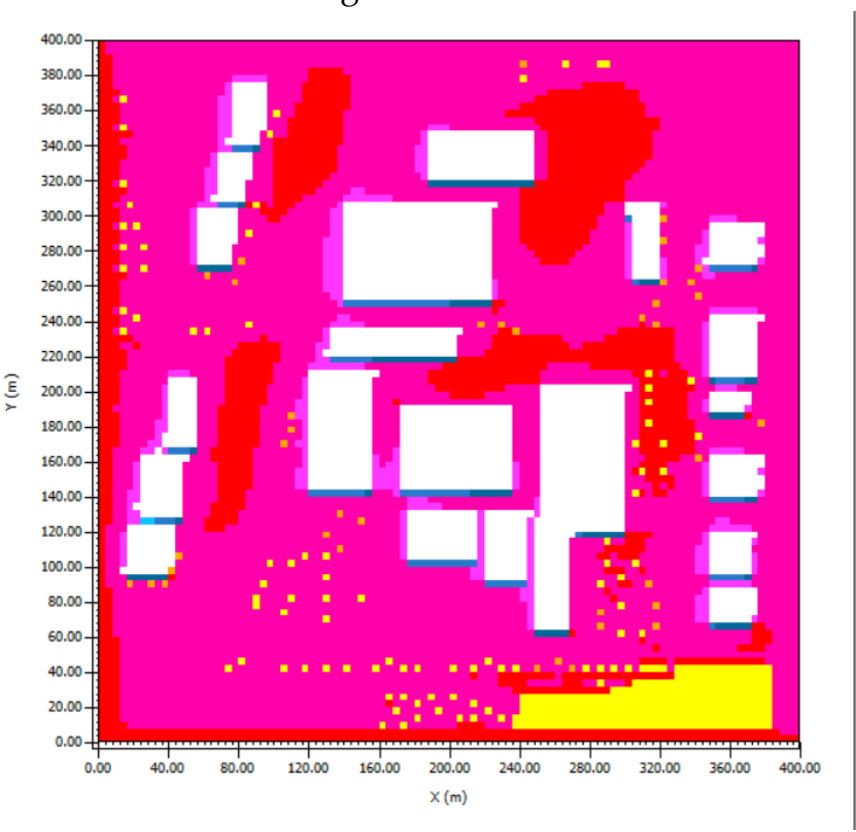

Figure 1: Boni 15.00 .01 05.04.2021

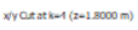

UTCI

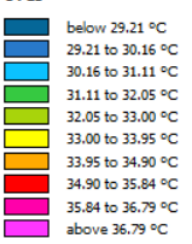

Min: $28.26^{\circ} \mathrm{C}$
$\operatorname{Max}: 37.7{ }^{\circ} \mathrm{C}$

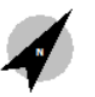

Fonte: Os autores (2021) 
$\mathrm{Na}$ tabela 2 são apresentados os resultados resumidamente. Verificou-se que os valores para os índices estudados de acordo com cada software dependem diretamente do período do dia.

Tabela 2: Resumo

\begin{tabular}{ccc}
\hline Dados & ENVI-met & Rayman \\
\hline T $_{\text {mrt }}$ & $9^{\circ} \mathrm{C}-68^{\circ} \mathrm{C}$ & $12^{\circ} \mathrm{C}-49^{\circ} \mathrm{C}$ \\
FVC & $0,83-0,91$ & $0,81-0,87$ \\
PET & $12,45^{\circ} \mathrm{C}-44,92^{\circ} \mathrm{C}$ & $11,9^{\circ} \mathrm{C}-33,4^{\circ} \mathrm{C}$ \\
UTCI & $15,35^{\circ} \mathrm{C}-36,53^{\circ} \mathrm{C}$ & $13,6^{\circ} \mathrm{C}-31,7^{\circ} \mathrm{C}$ \\
\hline
\end{tabular}

Fonte: Os autores

\section{CONCLUSÕES}

Destaca-se que o uso do ENVI-met e Rayman permitiram a análise de diversos parâmetros microclimáticos relevantes para o bem-estar e satisfação dos habitantes de uma cidade. $O$ uso de ferramentas computacionais como essas podem auxiliar na tomada de decisões no que diz respeito às alterações dos espaços urbanos.

As diferenças expressivas nos valores dos índices estudados acontecem nos períodos de incidência da radiação solar ou sombra. Os resultados fornecidos pelo software Rayman se mantiveram inferiores aos estimados pelo ENVI-met. Para comprovação do melhor modelo seria necessário realizar as medições in loco para efeitos comparativos.

\section{REFERÊNCIAS}

ANDRADE, P.C.R.; ROMERO, M.A.B. Análise do desempenho térmico dos materiais superficiais do contexto urbano do SIA/DF. In: Cadernos de Arquitetura e Urbanismo Paranoá. 2018. http://dx.doi.org/10.18830/issn.1679-0944.n22.2018.04

FERNANDES, L. C.; KRÜGER, E. L. Temperatura Radiante média obtida via termômetro de globo: análise crítica de dados de um estudo de campo. Revista de Arquitetura IMED, Passo Fundo, v. 8, n. 1, p. 147-163, set. $2019.2318-1109.2$ ISSN 20 Disponível https://seer.imed.edu.br/index.php/arqimed/article/view/3456/2363. Acesso em: 21 maio 2021. doi: https://doi.org/10.18256/2318-1109.2019.v8i1.3456.

RIBEIRO, K. F. A. et al. Análise do índice UTCI em diferentes tipos de cobertura na cidade de Cuiabá/MT. 2021. http://dx.doi.org/10.5380/abclima.v28i0.76079

MATZARAKIS, A; MAYER, H. Another kind of environmental stress: thermal stress. WHO News. N.18, p.7-10, 1996.

RUIZ, Á. et al. The globe thermometer in comfort and environmental studies in buildings. Revista de la construcción, v. 15, n. 3, p. 57-66, 2017. 
WALIKEWITZ, N. et al. The difference between the mean radiant temperature and the air temperature within indoor environments: A case study during summer conditions. Building and Environment, v. 84, p. 151-161, 2015.

WERNECK, D. R. Estratégias de mitigação das ilhas de calor urbanas: estudo de caso em áreas comerciais em Brasília-DF. Brasília. PPG FAU. Universidade de Brasília, 2018 